\title{
Hypothermia in Cardiac Arrest: A Meta-Analysis and Evidence-Based Appraisal of the Current Data
}

\author{
Cenker Eken \\ Department of Emergency Medicine, Akdeniz University Faculty of Medicine Antalya, Turkey
}

\begin{abstract}
Cooling the human body, particularly the brain, has been of concern for a long time. The resuscitation guideline by the American Heart Association that was released in 2010 declared therapeutic hypothermia, defined as maintaining the body temperature between $32^{\circ} \mathrm{C}$ and $34^{\circ} \mathrm{C}$ for $12-24 \mathrm{~h}$, as a Class I intervention in cardiac arrest patients secondary to ventricular fibrillation. However, the targeted temperature management (TTM) trial released after the aforementioned guideline has contrary results compared with the previous one. This evidence-based article aimed to appraise the current literature and perform a meta-analysis. (Eurasian J Emerg Med 2015; 14: 164-6)
\end{abstract}

Keywords: Therapeutic hypothermia, cardiac arrest

\section{Introduction}

Cooling the body, particularly the brain, has been of concern of human beings for a long time. Hypothermia has been proposed to be a neuroprotective intervention via the following mechanisms: decreasing cerebral metabolism, suppressing glutamate release, reducing neuro-inflammatory response, disrupting apoptotic pathways, etc (1). Evidence on the clinical effects of hypothermia in stroke and traumatic brain issues might be of interest in future articles.

Because the final neurological status is a matter either for physicians or patients who have return of spontaneous circulation (ROSC) secondary to cardiac arrest, hypothermia was of interest to researchers in the area as expected. This is an evidence-based article aimed to reappraise the data regarding therapeutic hypothermia cited in the 2010 resuscitation guideline and the targeted temperature management (TTM) trial that released following the aforementioned guideline.

\section{Analysis of the Data Cited in 2010 Guideline}

The resuscitation guideline by the American Heart Association that was released in 2010 declared therapeutic hypothermia, defined as keeping the body temperature between $32^{\circ} \mathrm{C}$ and $34^{\circ} \mathrm{C}$ for $12-24$ hours (h), as a Class I intervention in cardiac arrest patients secondary to ventricular fibrillation (VF) (2). The resuscitation council cited two articles when performing this recommendation. Therapeutic hypo- thermia was also recommended as Class Ilb in patients with cardiac arrest secondary to non-shockable rhythms. The lack of a randomized controlled trial conducted among patients with non-shockable rhythms was also highlighted in the same guideline.

The first article by Bernard et al. (3) was released in 2002 (3). The authors studied the patients with VF and who had a ROSC after resuscitation. The intervention was therapeutic hypothermia for $12 \mathrm{~h}$ compared to no cooling. Good outcome was defined as discharge to home or to a rehabilitation facility, whereas death in the hospital or transfer to a long-term nursing facility was accepted as the poor outcome. The final neurological status of the study patients was not established by a validated scale. The study by Bernard et al. (3) was a quasi-randomized study in which the study patients were assigned to the study groups according to the days of the month. Although the allocation was not concealed, intention-to-treat analysis was achieved. The baseline features of the study patients were similar between two groups, except for the high rate of bystander-performed cardiopulmonary resuscitation in the normothermia group (71\% vs. $49 \% ; p=0.05$ ). The study has a small sample size with 77 patients (43 vs. 34 patients), and the good outcome rate was $49 \%$ in the intervention group and $26 \%$ in the normothermia group $(p=0.046)$. The absolute risk reduction was $23 \%$, and number of patients needed to treat (NNT) was 5. However, the body temperature in the control group was over $37^{\circ} \mathrm{C}$ after $6 \mathrm{~h}$.

Correspondence to: Cenker Eken e-mail: cenkereken@gmail.com

Received: 09.11.2015 Accepted: 20.11.2015

oCopyright 2015 by Emergency Physicians Association of Turkey - Available online at www.eajem.com DOI: 10.5152/eajem.2015.98958 
The second study cited in the 2010 guideline was by Holzer et al. (4), which released in 2002. This study had a larger sample size than the study by Bernard et al. (3) Patients who had ROSC after a VF cardiac arrest were cooled for $24 \mathrm{~h}$ to maintain the body temperature between $32^{\circ} \mathrm{C}$ and $34^{\circ} \mathrm{C}$. The primary outcome was a favorable neurological outcome within 6 months defined as a Pittsburg cerebral-performance category of 1 or 2 . The study has a robust randomization method achieved by computerized blocks of 10 with allocation concealment. There were 275 patients assigned to the study groups (hypothermia group: 137 vs. normothermia group: 138). The favorable neurological outcome was $55 \%$ in the intervention group and $39 \%$ in the control group. The absolute risk reduction was $16 \%$, with an NNT value of 6 . Meanwhile, the body temperature in the control group was $37^{\circ} \mathrm{C}$ during the 48 -h period.

The TTM trial was a multi-center trial conducted in 36 intensive care units in Europe and Australia. Patients who had ROSC over $20 \mathrm{~min}$ after a cardiac arrest, presumed to be cardiac in origin regardless of initial rhythm, and a Glasgow Coma Scale Score of $<8$ composed the study population. Patients with an unwitnessed cardiac arrest with an initial rhythm of asystole were excluded. The intervention group underwent hypothermia with a goal to achieve a body temperature of $33^{\circ} \mathrm{C}$ for $28 \mathrm{~h}$, which was then compared with the normothermia group $\left(36^{\circ} \mathrm{C}\right)$. The poor outcome was defined as the Modified Rankin Scale Score of 4-6. The study has a robust methodology detailed in Table 1. The mortality rate was $48 \%$ in the hypothermia group and $47 \%$ in the normothermia group $(p=0.92)$. The poor neurological outcome was $52 \%$ in both groups. Despite the reported mortality rates in shockable and non-shockable rhythms, the neurological outcomes of these two subgroups has not been provided. The mortality rates in patients with shockable rhythms and non-shockable rhythms were $40.8 \%$ and $39.7 \%$, respectively (Hazard ratio: 1.06, 95\% GA: 0.84-1.34). Unlike the first two trials, the body temperature of patients in the control group in the TTM trial was maintained at $36^{\circ} \mathrm{C}$ during the 28 -h period.
The methodological quality and demographics of the trials are depicted in Tables 1 and 2.

\section{Meta-Analysis of Three Trials}

Two meta-analysis were performed, including three trials. The first meta-analysis considered death as the end point, and the poor outcome, including death and poor neurological outcome, was the end point for the second one. Figure 1 depicts the findings of meta-analysis evaluating death in three studies. There was a heterogeneity among the studies with an $\mathrm{I}^{2}$ value of $62 \%$ and a $\mathrm{p}$ value of 0.07 . Only the study by Holzer et al. (4) showed a statistically significant reduction in death favoring hypothermia. The pooled relative risk was 0.855 (95\% Cl: 0.673-1.087) for the random effects model and 0.912 (95\% Cl: 0.798-1.043) for the fixed effects model. Both pooled relative risks were statistically insignificant (Table 3 ).

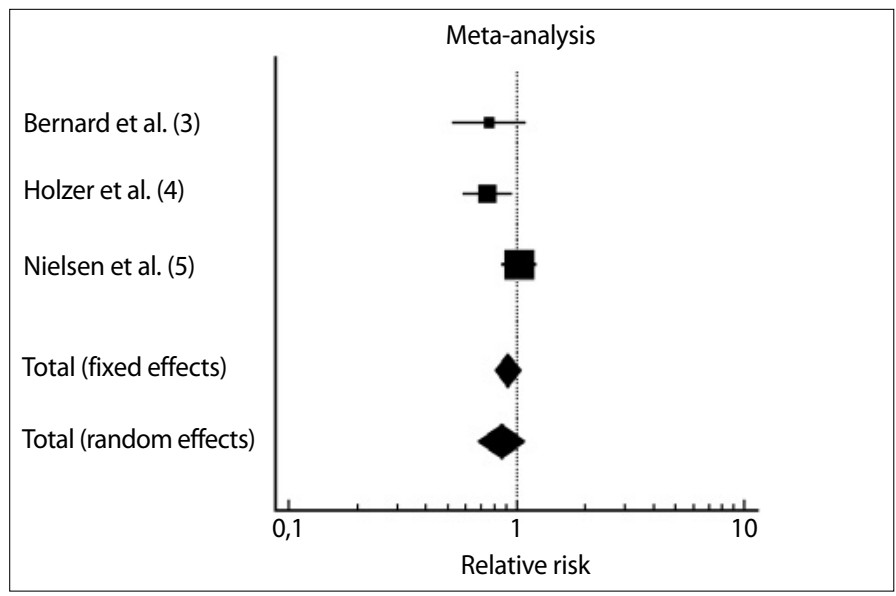

Figure 1. Meta-analysis displaying the pooled effect of hypothermia on death

Table 1. Methodological quality of trials comparing hypothermia with normothermia

\begin{tabular}{|c|c|c|c|c|c|}
\hline Study & Randomization & Concealment & $\begin{array}{l}\text { Intention } \\
\text { to Treat }\end{array}$ & $\begin{array}{l}\text { Blind Assessment } \\
\text { of the Outcome }\end{array}$ & Completeness Follow-up \\
\hline Bernard et al. (3) & $\begin{array}{c}\text { Randomized to the days of } \\
\text { the month (quasi-randomized) }\end{array}$ & No & Yes & Yes & $\begin{array}{c}5 \text { patients were transferred } \\
\text { to another ICU }\end{array}$ \\
\hline Holzer et al. (4) & $\begin{array}{l}\text { Randomization by } \\
\text { computerized blocks }\end{array}$ & $\begin{array}{c}\text { Yes } \\
\text { (sealed envelopes) }\end{array}$ & Yes & Yes & $\begin{array}{l}\text { One patient in each group } \\
\text { was lost to follow-up for } \\
\text { neurological status }\end{array}$ \\
\hline Nielsen et al. (5) & $\begin{array}{l}\text { Central randomization } \\
\text { by computerized blocks }\end{array}$ & Yes & Yes & Yes & $\begin{array}{l}\text { Although } 950 \text { patients were } \\
\text { randomized, } 939 \text { patients were } \\
\text { included into the ITT analysis (four } \\
\text { were withdrawn at their own request) }\end{array}$ \\
\hline
\end{tabular}

Table 2. Demographics of the trials comparing hypothermia to normothermia

\begin{tabular}{|l|c|c|c|}
\hline Study & Intervention & Number of participants & Outcome \\
\hline Bernard et al. (3) & Hypothermia vs. Normothermia & 43 vs. 34 & $\begin{array}{c}\text { Discharge to home or to a rehabilitation } \\
\text { facility was regarded as a good outcome }\end{array}$ \\
\hline Holzer et al. (4) & Hypothermia vs. Normothermia & 136 vs. 137 & $\begin{array}{c}\text { Pittsburgh cerebral performance category of 1 } \\
\text { (good recovery) and 2 (moderate disability) at 6 months. }\end{array}$ \\
\hline Nielsen et al. (5) & Hypothermia vs Normothermia & 473 vs. 466 & $\begin{array}{c}\text { The poor outcome was defined as the } \\
\text { Modified Rankin Scale Score of 4-6 at 6 months. }\end{array}$ \\
\hline
\end{tabular}


Table 3. Numerical exhibition of meta-analysis for death

\begin{tabular}{|l|c|c|c|c|}
\hline Study & Intervention & Controls & Relative risk & 95\% Cl \\
\hline Bernard et al. & $22 / 43$ & $23 / 34$ & 0.756 & $0.521-1.099$ \\
\hline Holzer et al. & $56 / 137$ & $76 / 138$ & 0.742 & $0.577-0.954$ \\
\hline Nielsen et al. & $153 / 375$ & $150 / 377$ & 1.025 & $0.862-1.220$ \\
\hline Total (fixed effects) & $231 / 555$ & $249 / 549$ & 0.912 & $0.798-1.043$ \\
\hline Total (random effects) & $231 / 555$ & $249 / 549$ & 0.855 & 0.673 to 1.087 \\
\hline
\end{tabular}

Table 4. Numerical exhibition of meta-analysis for death and poor neurological outcome

\begin{tabular}{|l|c|c|c|c|}
\hline Study & Intervention & Controls & Relative risk & 95\% Cl \\
\hline Bernard et al. (3) & $22 / 43$ & $25 / 34$ & 0.696 & $0.488-0.992$ \\
\hline Holzer et al. (4) & $61 / 136$ & $83 / 137$ & 0.740 & $0.588-0.932$ \\
\hline Nielsen et al. (5) & $245 / 469$ & $239 / 464$ & 1.014 & $0.896-1.148$ \\
\hline Total (fixed effects) & $328 / 648$ & $347 / 635$ & 0.924 & $0.833-1.026$ \\
\hline Total (random effects) & $328 / 648$ & $347 / 635$ & 0.831 & $0.639-1.079$ \\
\hline
\end{tabular}

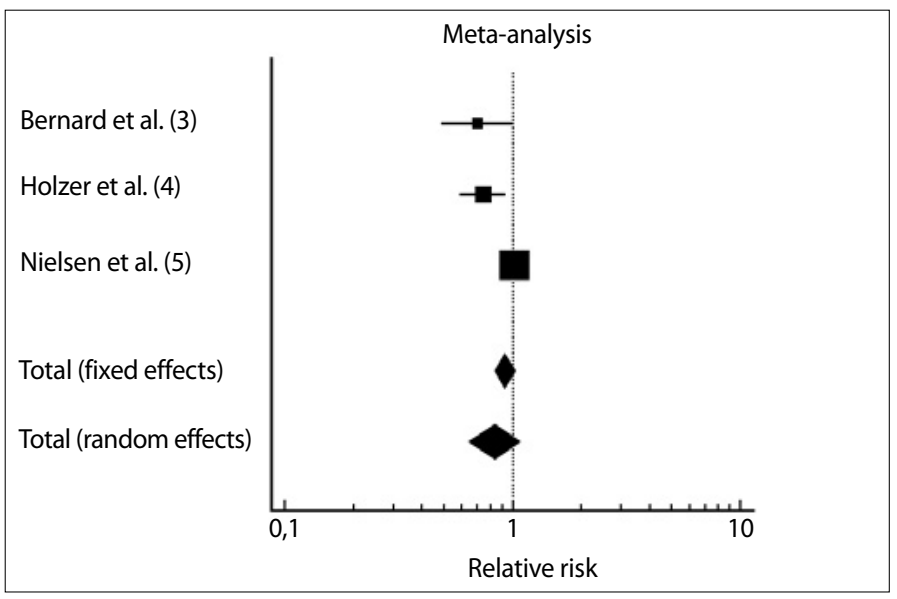

Figure 2. Meta-analysis displaying the pooled effect of hypothermia on death and poor neurological outcome

Figure 2 depicts the second meta-analysis evaluating death and poor neurological outcome in three studies. There was a heterogeneity among the studies with an $\mathrm{I}^{2}$ value of $75 \%$ and a $\mathrm{p}$ value of 0.01 . Although studies by Bernard et al. and Holzer et al. showed a statistically significant reduction in poor outcome, there was no difference in the TTM trial. The pooled relative risk was $0.924(95 \% \mathrm{Cl}$ : 0.833-1.026) for the fixed effects model and 0.831 (95\% Cl: 0.639 to $1.079)$ for the random effects model. Both results were statistically insignificant (Table 4).

\section{Therapeutic Hypothermia for Non-Shockable Rhythms}

Therapeutic hypothermia was stated to be a Class Ilb recommendation in the 2010 guideline, with the lack of a randomized controlled trial avoiding a robust conclusion. The TTM trial is the only randomized controlled trial reporting data regarding these patients as a subgroup analysis. According to the TTM trial, there were 98 pa- tients in the intervention group and 88 patients in the control group, with a mortality rate of $83.7 \%$ vs. $84 \%$, respectively (dif: $0.41 \%, 95 \%$ $\mathrm{Cl}:-11 \%-11.6 \%)$. The data regarding neurological outcome in patients with non-shockable rhythm was not reported in the TTM trial.

\section{Conclusion}

The biggest trial so far, the TTM trial, showed no difference between therapeutic hypothermia and normothermia in cardiac arrest patients with an initial either shockable rhythm or non-shockable rhythm. Although the first two trials on the issue showed beneficial effects, their sample sizes were small, leading to results that are prone to random error and chance factor. The meta-analysis also showed no statistically significant superiority of therapeutic hypothermia when compared to normothermia.

\section{References}

1. Wu TC, Grotta JC. Hypothermia for acute ischaemic stroke. Lancet Neurol 2013; 12: 275-84. [CrossRef]

2. Peberdy MA, Callaway CW, Neumar RW, Geocadin RG, Zimmerman JL, Donnino M, et al. Post-cardiac Arrest Care: 2010 American Heart Association Guidelines for Cardiopulmonary Resuscitation and Emergency Cardiovascular Care. Circulation 2010; 122: S768-S86. [CrossRef]

3. Bernard SA, Gray TW, Buist MD, Jones BM, Silvester W, Gutteridge G, et al. Treatment of Comatose Survivors of Out-of-Hospital Cardiac Arrest with Induced Hypothermia. N Engl J Med 2002; 346: 557-63. [CrossRef]

4. Holzer M, Cerchiari E, Martenz P, Roine R, Sterz F, Eisenburger F, et al.; Hypothermia after Cardiac Arrest Study Group. Mild therapeutic hypothermia to improve the neurologic outcome after cardiac arrest. N Engl J Med 2002; 346: 549-56. [CrossRef]

5. Nielsen N, Wetterslev J, Cronberg T, Erlinge D, Gasche $\mathrm{Y}$, Hassager $\mathrm{C}$, et al. Targeted temperature management at $33^{\circ} \mathrm{C}$ versus $36^{\circ} \mathrm{C}$ after cardiac arrest. N Engl J Med 2013; 369: 2197-206. [CrossRef] 